\title{
PRECIOSA: AS CONSEQUÊNCIAS JURÍDICAS E EXTRAJURÍDICAS DA INVISIBILIDADE SOCIAL
}

\author{
Ana Virgínia Gabrich Fonseca Freire Ramos* \\ Camila Martins de Oliveira**
}

Resumo: Sentir-se invisível em uma sociedade de tantos atores é uma situação cada vez mais comum. As várias formas de violência acabam por contribuir para essa situação: é cada vez mais alarmante o número de pessoas, principalmente mulheres, vítimas de violência. $\mathrm{O}$ artigo busca analisar as consequências jurídicas dessa situação a partir da história fictícia de Claireece Preciosa, apresentada pelo filme Preciosa: uma história de esperança. A metodologia utilizada, é a pesquisa exploratória apoiada em levantamento bibliográfico e estudo de caso cinematográfico. O método é o hipotético-dedutivo.

Palavras-chave: Invisibilidade social; Violência; Mulher; Direito Penal; Cinema.

\section{PRECIOUS: THE LEGAL AND EXTRA-JURIDICAL CONSEQUENCES OF SOCIAL INVISIBILITY}

Abstract: Feeling invisible in a society of so many actors is an increasingly common situation. The various forms of violence end up contributing to this situation: the number of people, especially women, who are victims of violence is increasingly alarming. The article seeks to analyze the legal consequences of this situation from the fictional story of Claireece Preciosa, presented by the film Preciosa: a story of hope (portuguese title). The methodology used is the exploratory research supported by a bibliographical survey and a case study. The method is hypothetico-deductive.

Key-words: Social invisibility; Violence; Woman; Criminal Law; Movie theater.

\footnotetext{
* Doutoranda em Direito pela Escola Superior Dom Helder Câmara (DHC); Mestre em Direito pela DHC; Especialista em Direito Ambiental pelo Centro de Estudos em Direito e Universidade Gama Filho; Mestre em Direito pela Escola Superior Dom Helder Câmara; Bacharel em Direito pela Pontifícia Universidade Católica de Minas Gerias - PUC/Minas; Professora de Direito Constitucional e Teoria do Estado da DHC; Advogada. E-mail: gabrichfreire@ gmail.com

** Doutoranda em Direito pela Escola Superior Dom Helder Câmara; Mestre em Direito pela Escola Superior Dom Helder Câmara; Especialista em Direito Público pela Centro de Estudos em Direito e Universidade Gama Filho; Bacharel em Direito pela Pontifícia Universidade Católica de Minas Gerias - PUC/Minas; Professora de Direito Penal e Legislação Penal Especial da Escola Superior Do Helder Câmara; Professora de Direito Penal de Cursos de Formação da Polícia Militar de Minas Gerais; e Advogada. E-mail: oliveira_camilam@yahoo.com.br
} 


\section{CONSIDERAÇÕES INICIAIS}

A obra analisada é construída tendo como enredo central a violência doméstica e familiar sofrida pela personagem principal, uma adolescente de 17 anos que sofre as mais diversas situações violentas durante a vida. Claireece Preciosa Jones é vítima de violência sexual a qual tem como autor de vários crimes de estupro o próprio pai. É vítima de violência física e psicológica de autoria da mãe que em várias passagens da narrativa utiliza palavras depreciativas como vagabunda, vaca, inútil, burra para se referir à filha bem como agride sua integridade corporal constantemente. A jovem é, por diversas vezes, ferida em sua dignidade moral ao serem utilizados elementos discriminatórios como gorda, baleia, burra. Por fim tornase vítima do sistema penal ao ser transformada em jovem infratora negra e pobre.

Com a finalidade de elucidar cada uma dessas situações, serão trazidas à análise em tela as narrativas das cenas de violência abordadas na obra cinematográfica e, posteriormente, comentadas à luz da invisibilidade social e do direito brasileiro.

Assim, o artigo se desenvolverá tendo com ponto de partida o enredo do filme Preciosa: uma história de esperança, que será utilizado para ilustrar as teorias aqui abordadas.

O objetivo geral será criar um paralelo entre o enredo apresentado e questões jurídicas ali presentes, de maneira a elucidar os problemas daí advindos e como o direito se apresentará nessa situação. Além disso, a questão da invisibilidade social será explorada, de maneira a demonstrar como a sociedade contribui para a criação de cenários de violência e reforço de estereótipos preestabelecidos.

A pesquisa tem um aspecto transdisciplinar, e se desenvolverá tendo por base dados secundários, extraídos de livros, artigos científicos e sites especializados, além da obra cinematográfica supracitada.

Com base no seu objetivo geral, a pesquisa se caracterizará como exploratória. O método utilizado será o hipotético-dedutivo e as técnicas utilizadas serão o estudo de caso fictício (apresentado pelo filme) e a pesquisa bibliográfica.

Para tanto, o texto se dividirá em capítulos. A primeira parte abordará a questão da invisibilidade social, por meio de argumentos sociológicos e filosóficos. O capítulo seguinte abordará as consequências jurídicas das situações apresentadas pelo filme em questão, apresentando cada tipo de violência sofrida por Preciosa e como essa violência é retratada no 
cotidiano atual. Após, é exposto um capítulo com as consequências extrajurídicas das situações de violência presentes no filme e, por fim, são apresentadas as considerações finais.

\title{
2 DA INVISIBILIDADE SOCIAL
}

Claireece Preciosa Jones se sentia invisível. A invisibilidade se fazia presente em várias situações: no desprezo e violência da mãe, nas atitudes brutais do pai, nas palavras dos colegas de escola, nas ruas, na imagem refletida no espelho... tudo fazia com que ela se sentisse diminuída, invisível para os outros e para si mesma.

Júlia Catarina de Sá Pinto Tomás, ao discorrer sobre a invisibilidade social a partir de uma perspectiva fenomenológica, afirma que:

O desprezo social e o não-reconhecimento dão origem ao sentimento de invisibilidade. $\mathrm{Na}$ sociedade do espetáculo na qual nós vivemos, o invisível tende a significar o insignificante. Com efeito, múltiplos sentimentos estão ligados ao sentimento central de ser invisível para os outros: a vergonha, a paranoia, a impressão de insucesso pessoal, o isolamento, a clandestinidade. (TOMÁS, 2008, p. 3).

Assim, todas as atitudes em volta de Preciosa contribuíam para o aumento desse sentimento de invisibilidade. Entretanto, é preciso que alguns pontos sejam considerados. Tomás (2008), ainda discorrendo sobre a invisibilidade social, aponta algumas questões interessantes, dentre elas a fenomenologia do inaparente, atribuída a Heidegger. Explica Tomás (2008) que “o movimento do 'inaparecer' é um movimento intencional significante em si” (TOMÁS, 2008, p. 3).

A intencionalidade mencionada pela autora, está também ligada à psicologia objetiva. Para os psicólogos da forma, nós nos damos conta das formas por um ato de pensamento, ou seja, é a nossa percepção das formas que organizam e dão sentido aos elementos apercebidos. E este ato de olhar, de perceber, é um ato intencional, que ilustra a relação que cada indivíduo tem com o mundo (TOMÁS, 2008, p. 3-5).

\begin{abstract}
A percepção é a constituição primeira do objecto, ora a percepção é construída pela base comportamental socio-cultural do indivíduo que olha. O que nos conduz a pensar que o que nós vemos (ou não vemos) é, no fundo, o resultado de uma vontade própria (que pode ser, por muito paradoxal que pareça, involuntária). (TOMÁS, 2008, p. 4).
\end{abstract}

Nesse sentido, a percepção que Preciosa tinha de si mesma era uma construção daquilo que lhe era atribuído, de como ela via o mundo e de como as pessoas a percebiam, por se tratar 
também de uma construção sociocultural. A sua consciência de si mesma, nesse contexto inicial, não a levaria a outro resultado, senão a invisibilidade.

Mas, "quando a consciência é consciente da atitude natural apercebe-se finalmente que não é o mundo que lhe é dado, mas é ela, ao contrário, que dá sentido ao mundo. Portanto se a consciência é doadora de sentido, o acto de ver transforma-se numa operação e mesmo talvez numa criação" (TOMÁS, 2008, p. 4). Esse sentido de consciência é apresentado no filme quando Preciosa muda de escola e passa a ter contato com a Professora Blu Rain e novas colegas de sala.

A passagem para a nova escola, uma escola alternativa, é ponto crucial na trama. Ao chegar à nova escola Preciosa, já grávida do seu segundo filho, recebe atenção por parte da professora - e aos poucos também por parte das colegas de sala - e começa a se perceber de outra maneira. Ao começar seu processo de alfabetização, Preciosa ganha algo além das palavras, que é a consciência do seu papel no mundo e, acima de tudo, do seu papel consigo mesma, passando a entender que ela é capaz de dar sentido às coisas ao seu redor, e não apenas ficar (ou sentir-se) indiferente ao mundo.

Essa mudança de percepção gera uma mudança de atitude da protagonista que, de invisível, começa a ganhar voz. Assim, seus problemas e traumas vão ganhando corpo por meio da escrita no caderno/diário - um exercício cotidiano passado pela Professora - e um futuro começa a ser desenhado para Preciosa, um futuro possível e não apenas imaginado em seus sonhos.

É a intencionalidade da consciência e o seu modo transcendental que nos abre a possibilidade de distinguir um lado objectivo e um lado subjectivo. Por isso quando por exemplo um casal dá a mão um ao outro, objectivamente dão simplesmente a mão, subjectivamente, um mundo de sonhos, recordações e desejos são partilhados através este gesto (TOMÁS, 2008, p. 4).

Assim, Preciosa passa a ter uma consciência diferente de si mesma, o que é evidenciado com o nascimento de seu segundo filho, Abdul. Ainda na maternidade lhe é apresentada a possibilidade de dar Abdul para adoção, sob o argumento de que ela não teria condições de criar o bebê e que uma família substituta seria melhor para ele. Entretanto, Preciosa é firme ao sustentar que o bebê precisava dela e que ela teria, sim, condições para crialo. Nesse momento, percebe-se o lado subjetivo da consciência da protagonista, que passa a enxergar possibilidades inexistentes até então, se vendo como uma pessoa capaz, capaz inclusive de cuidar de outra vida. 
Essa mudança de atitude de Preciosa pode ser explicada, ainda, pelo que Alfred Schütz, citado por Tomás (2008, p. 5), chamaria de um processo contínuo de tipificações, organizado em torno do aqui e do agora do ator social. "Existe portanto na consciência humana uma dimensão de proximidade e de distância no tempo e no espaço, sendo esta acompanhada por outra dimensão: a intimidade e o anonimato" (TOMÁS, 2008, p. 4). Quando Preciosa começa a fazer parte de um círculo social, formado dentro da escola, e começa a conviver com pessoas que lhe davam atenção, seu sistema de tipificação do eu-aqui-agora muda para algo positivo, e suas atitudes passam a refletir a sua nova percepção de mundo. "Os níveis de interacção vão depender da intimidade e do interesse que o indivído oferece ao outro. Portanto podemos afirmar que as tipificações do Outro sofrem a interferência do individo que tipifica" (TOMÁS, 2008, p. 5).

Interessante ressaltar que o cenário anteriormente apresentado para a protagonista (somente de emoções e situações negativas) era um cenário do "não ver", ou seja, aquelas pessoas que faziam parte do seu círculo social, apesar de saberem de todos os problemas enfrentados por Preciosa, optaram por não ver o que acontecia. Isso se torna fundamental para a argumentação até aqui desenvolvida, pois se o estado de consciência passa pela atitude intencional e pela percepção, o ato de não ver também é uma escolha consciente do indivíduo, que orienta seu agir significativamente para isso. Assim, "se agir implica escolher, então o nãoreconhecimento de outrém torna-se num acto intencional, sem porém querer dizer que é voluntário" (TOMÁS, 2008, p. 6).

Essa involuntariedade apresentada pela autora pode ser vista ao final do filme, na conversa entre a mãe de Preciosa e a Assistente Social, quando esta pergunta para a mãe o porquê de ela não ter defendido a filha dos abusos sexuais do pai, já que ela tinha consciência dos fatos. A mãe, nesse momento, tenta demonstrar uma falta de escolhas - que pode ser colocada em dúvida - e uma involuntariedade na sua atitude de não reação o que, posteriormente, “justificaria” (na percepção da mãe) a sua raiva pela filha.

A construção do enredo, mesclando fatos presentes, passados, a própria percepção de Preciosa de si mesma e seus sonhos, ilustra bem a questão aqui apresentada sobre a invisibilidade social. Ser invisível numa sociedade de tantos atores sociais não quer dizer não existir, a invisibilidade transcende o eu e alcança o nós. Uma pessoa invisível só é invisível porque nós a fazemos perceber assim. A construção de estereótipos, de padrões estéticos, de um mundo cada vez mais individualista faz com que o outro deixe de existir, e ao não se enxergar o outro, o eu também vai diminuindo até se tornar invisível. 
Apresentadas as primeiras percepções acerca da invisibilidade social, passa-se a analisar as consequências jurídicas advindas das várias situações de violência presentes no filme.

\section{CONSEQUÊNCIAS JURÍDICAS}

Apresentadas as questões iniciais sobre a invisibilidade social, algumas consequências jurídicas merecem ser analisadas.

\subsection{Violência doméstica e familiar contra a mulher}

A proteção, ao menos simbólica das mulheres, a partir da análise de elementos jurídicos e éticos, já é uma realidade nacional bem como mundial. É notória a ampliação do sistema normativo, efetivado e em construção, em prol dos direitos das mulheres na maior parte da vezes influenciado diretamente e, até mesmo indiretamente, pelas reinvindicações formuladas pelos movimentos feministas.

Tanto a Constituição brasileira de 1988 quanto alguns documentos nacionais e internacionais acolheram uma série de reivindicações formuladas pelos movimentos feministas como a igualdade geral entre homens e mulheres (artigo $5^{\circ}, \mathrm{I}$ ), a igualdade no âmbito da família (artigo 226, §5 $5^{\circ}$, a proibição da discriminação no mercado de trabalho (artigo $7^{\circ}, \mathrm{XXX}$ ), a proteção especial da mulher do mercado de trabalho (artigo $7^{\circ}, \mathrm{XX}$ ), o planejamento familiar como uma livre decisão do casal (artigo 226, parágrafo $7^{\circ}$ ) e o dever do Estado de coibir a violência doméstica no âmbito das relações familiares (artigo 226, parágrafo $8^{\circ}$ ) (BARSTED, 2011, p. 61).

No campo penal podem ser citados como avanços, a partir das pautas feministas, a previsão do crime de assédio sexual (Lei 10.224, de 2001), a notificação compulsória, em território nacional, de casos de violência contra a mulher que for atendida em serviços de saúde públicos ou privados (Lei 10.888, de 2003), a retirada do Código Penal do conceito de mulher honesta e da possibilidade de extinção da penalidade do agressor sexual em caso de superveniente matrimônio com a vítima (Lei 11.106 de 2005), a criação de mecanismos de coibição da violência doméstica e familiar contra a mulher (Lei 11.340 de 2006) e a inclusão 
do feminicídio no Código Penal como qualificadora do crime de homicídio pela Lei 13.104 de 2015.

No Brasil a violência doméstica e familiar contra a mulher tem seu principal aporte normativo disposto na Lei 11.343/06, de iniciativa do Poder Executivo após ser elaborada por um consórcio de entidades feministas. Intitulada Lei Maria da Penha, a lei federal carrega este nome em virtude da condenação do Estado Brasileiro, no Relatório n. 54 pela Comissão Interamericana de Direitos Humanos da Organização dos Estados Americanos, por ter sido omisso, negligente e tolerante em relação às violências domésticas e familiares sofridas pela biofarmacêutica Maria da Penha Fernandes praticadas por seu ex-marido enquanto viviam juntos. Não serão abordados detalhes do caso na Corte, mas é importante ressaltar que a luta por igualdade de gênero, na seara brasileira, ainda se faz necessária pois mostram-se muito recentes as primeiras tentativas de erradicação da forma de violência supracitada.

Nesse sentido dispõe Maria Berenice Dias, jurista que tem dedicado parte importante de suas pesquisas jurídicas à área em questão, ao afirmar que com a desculpa da sacralidade da família os diversos atores sociais do Estado e extra-Estado sempre optaram por não intervir nas relações domésticas dos indivíduos, uma vez que seria inconcebível com a ideia de próprio Estado Liberal intervir no "lar, doce lar". (p. 31, 2015). As mulheres sempre foram educadas para a manutenção da ordem familiar e não interferir no funcionamento deste é ideia advinda do patriarcado sustentado pela dominação masculina e, consequente, submissão feminina. Alerta a autora que:

Desde que o mundo é humano, a mulher sempre foi discriminada, desprezada, humilhada, coisificada, objetivizada, monetarizada. Ainda assim, a violência de que as mulheres são vítimas no reduto doméstico, nunca mereceu a devida atenção, nem da sociedade, nem do legislador, e muito menos do Judiciário. (DIAS, p. 31, 2015)

No entanto, após a supracitada condenação do Brasil perante órgão internacional, não foi mais possível a continuidade da omissão em relação a realidade tão aflitiva que afeta vários lares brasileiros: a violência doméstica e familiar.

A Lei Maria da Penha, que não será propriamente o objeto desta análise, mas é fator importante para entender as consequências jurídicas da violência no caso brasileiro da obra cinematográfica Preciosa, enumera cinco formas de violência doméstica e familiar contra a mulher: física, psicológica, sexual, patrimonial e moral.

No filme, Preciosa sofre diversas das violências acima elencadas, portanto, analisarse-á cada uma delas à luz da Lei 11.340/06. A primeira violência objeto de análise será a de 
ordem sexual. A jovem é estuprada por seu pai em várias passagens e engravida por duas vezes do criminoso, tendo concebido os filhos em ambas as oportunidades. Fruto de uma das violências sexuais é a bebê apelidada de "mongo" nasce com síndrome de Down e se mantém sob os cuidados da avó materna da protagonista do filme, uma vez que esta não tem condições financeiras e muito menos psicológicas para cuidar de uma criança.

Algum tempo após a primeira gestação Preciosa novamente se encontra na posição de gestante de um segundo filho, fruto também do violento estupro do ente paterno. A parte inicial da obra narra justamente a vivência dessa gravidez até os primeiros meses da criança, a qual diferentemente da primeira filha recebe o nome Abdul e permanece sob os cuidados da própria mãe, protagonista do filme.

A violência sexual disposta no art. $7^{\circ}$, III, da Lei 11.340/06 "pode ser entendida como qualquer conduta que a constranja a presenciar, a manter ou a participar de relação sexual não desejada, mediante a intimidação, ameaça, coação ou uso da força (...)”. (BRASIL, 2006)

Entendido tal conceito fica clara a situação de violência sexual a qual se submeteu a protagonista ao ser violentada sexualmente pelo pai. Transportando para a realidade jurídica brasileira aplicar-se-ia o disposto no Código Penal, art. 213, crime de estupro com ação penal pública incondicionada pela menoridade da vítima e com agravante pela situação de violência doméstica e familiar disposta no art. 61, II, $f, \mathrm{CP}$.

Apesar de ser um passo importante no combate à violência em questão a Lei 11.340/06 ainda pertence ao sistema de justiça criminal brasileiro (SJC), com todas as suas mazelas. Importantes são as considerações da criminologia feminista para ser melhor trabalhada essa questão, já que o SJC é alheio à realidade das mulheres por não reconhecer a desigualdade de gênero dominante na sociedade, tornando-se, na maior parte das vezes, ineficaz na proteção destas contra a violência doméstica e familiar, principalmente quando envolve crimes contra a dignidade sexual.

Vera Regina Pereira Andrade, ao analisar o modo como o sistema de justiça criminal atua nas questões que envolvem mulheres, aponta a ineficácia deste em dois sentidos. No sentido fraco o SJC não se interessa pela vítima por isso não a escuta, não verifica suas pretensões, não compreende as situações de violência e não gere o conflito existente, preocupando-se somente em formalizar dados sem se importar em analisar os comportamentos envolvidos à luz dos debates sobre gênero. Já no sentido forte o SJC quanto às mulheres "duplica a violência exercida contra elas e as divide, sendo uma estratégia excludente que afeta a própria unidade (já complexa) do movimento feminista" no momento em que a vítima passa 
do controle familiar para o controle formal do Estado revivendo as situações culturais de humilhação, violência, discriminação baseada no gênero etc. (2005, p. 75). Conforme a autora:

\begin{abstract}
E, ao incidir sobre a vítima mulher a sua complexa fenomenologia de controle social, que representa, por sua vez, a culminação de um processo de controle que certamente inicia na família, o SJC duplica, em vez de proteger, a vitimação feminina, pois além da violência sexual representada por diversas condutas masculinas (estupro, atentado violento ao pudor etc.), a mulher torna-se vítima da violência institucional plurifacetada do sistema, que expressa e reproduz, por sua vez, dois grandes tipos de violência estrutural da sociedade: a violência das relações sociais capitalistas (a desigualdade de classes) e a violência das relações sociais patriarcais (traduzidas na desigualdade de gênero), recriando os 76 estereótipos inerentes a estas duas formas de desigualdade, o que é particularmente visível no campo da violência sexual. (ANDRADE, p. 75, 2005)
\end{abstract}

Cabe ressaltar que muitas mulheres, assim como acontece com Claireece no filme, não se dão conta que são vítimas de violência sexual num primeiro momento, justamente pela estrutura patriarcal de violência a que estão sempre submetidas e que muitas vezes geram sensação de normalidade. Tal consideração traz à tona conceitos como violência estrutural em contraposição à violência individual.

Conforme Andrade:

As mulheres começam a dar-se conta de que o estupro (assim como os maus-tratos, o incesto, a prostituição, o assédio sexual no trabalho etc.) são fenômenos de uma estrutura de poder, a existente entre homens e mulheres, e o argumento da violência estrutural foi cedendo lugar ao argumento da violência estrutural. (2005, p. 96)

A segunda violência de que foi vítima Preciosa é a violência física. São várias as passagens em que a protagonista sofre tal violência, mas para ilustrar pode ser narrada uma cena que a protagonista retorna à casa onde mora com a mãe dias depois de ter tido seu segundo bebê, fruto do estupro cometido pelo pai, e ao chegar no local a mãe em tom raivoso ordena que a garota cozinhe algo para o jantar. A menina está na cozinha enquanto a mãe segura o recém-nascido no colo e num gesto também esta passa a agredir Preciosa com panelas, joga a televisão na direção da filha, dentre outros atos violentos até que a jovem fuja, juntamente com seu filho, do apartamento da família.

A Violência física conforme o art. $7^{\circ}$, I, da Lei Maria da Penha pode ser entendida como "qualquer conduta que ofenda sua integridade ou saúde corporal." (BRASIL, 2006). No caso em tela fica nítida a violência sofrida. O que merece ser objeto de análise por ora é a 
possibilidade de aplicação, em casos como estes, da Lei Maria da Penha uma vez que a autora é mulher, no caso mãe da vítima.

Encontra-se pacificado na doutrina e jurisprudência que a passividade a que se refere a lei em comento tem como figura central a mulher, apesar de existirem divergências acerca de sua aplicação a transexuais e travestis.

De outro lado, as questões relativas ao sujeito ativo da violência merecem considerações especiais nesta análise. Conforme o próprio Superior Tribunal de Justiça já decidiu a mulher também pode ser sujeito ativo de crimes que envolvam violência doméstica e familiar. O próprio Superior Tribunal de Justiça já reconhece a possibilidade de autoria em relação à Lei Maria da Penha por mães, companheiras, irmãs etc. (STJ, 2019). Dessa forma verifica-se que o agressor pode ser tanto um homem quanto uma mulher, no caso em tela a própria mãe de Preciosa.

Ainda cabe narrar episódios em que a protagonista foi vítima de psicológica, esta entendida como "qualquer conduta que lhe cause dano emocional e diminuição de autoestima ou que lhe prejudique e perturbe o pleno desenvolvimento (...) mediante ameaça, constrangimento, isolamento, vigilância constante, perseguição contumaz, insulto, chantagem, ridicularização (...)” nos termos do art. $7^{\circ}$, II da Lei Maria da Penha. (BRASIL, 2006)

Para ilustrar uma das situações pode ser citada a cena em que a adolescente é chamada de "gorda", "imprestável” e "feia" pela genitora numa típica situação de indignidade.

\subsection{Discurso de ódio, injúria racial e gordofobia}

Outra forma de violência que pode ser verificada na obra objeto de análise é a violência moral, não necessariamente ocasionada no ambiente familiar ou doméstico, portanto nem sempre de possível aplicação da Lei 11.340/06.

Nas cenas em que a mãe de Preciosa ofende a dignidade ou decoro de sua filha com as expressões supracitadas pode ser verificada a prática de crime de injúria conforme o disposto no art. 140 do nosso Código Penal com agravante no caso concreto pela situação familiar e doméstica como já esclarecido no item 3.1. No entanto, nas cenas em que a ofensa moral ocorre em contextos alheios à realidade do lar ou da família não mais pode-se falar em aplicação da Lei Maria da Penha com a agravante supracitada. 
Nos casos em que os colegas de classe e grupos na rua ofendem a protagonista, como na cena em que ela passava numa calçada e um grupo de homens a ofende com expressões de ódio, também pode ser vislumbrada uma hipótese de crime de injúria.

$\mathrm{Na}$ análise aqui pretendida não pode ser deixado de lado o fato duas condições que geraram em diversas cenas do filme situações de violências, o fato da protagonista ser negra e acima do peso tornando-se vítima frequente da intitulada "gordofobia" e de preconceito racial.

\subsection{Violência sistêmica penal}

A protagonista do filme, além das violências já enumeradas, também sofre as violências sistêmicas do direito penal. Os dois exemplos mais claros na obra podem ser verificados nas seguintes cenas. Na primeira, Preciosa engana uma atendente de lanchonete e subtraí um balde de frango frito, que é comido em seguida. Na segunda cena, a jovem violentamente empurra uma vizinha que é criança contra parede. Em ambas as passagens resta claro que a adolescente se torna refém do próprio sistema penal altamente crimonógeno e seletivo que transforma vulneráveis em criminosos. É sabido que, se trouxermos o caso para o debate jurídico brasileiro, Preciosa não será considerada tecnicamente uma criminosa, mas sim uma menor infratora sujeita às normas contidas no Estatuto da Criança e Adolescente. Tal fato não torna distante as afirmações já realizadas no começo deste parágrafo acerca do caráter seletivo e criminógeno do nosso sistema penal ou aplicado aos menores infratores. Jovens, pobres e negros são as "escolhas" constantes do nosso sistema criminal conforme pode se verificar no sistema prisional brasileiro.

Apesar ser o homem pobre, jovem e negro uma escolha padrão do sistema penal, é crescente a mulher com as mesmas características que passa, cada vez mais, a ser alvo do sistema de justiça criminal nos países latino americanos, principalmente no Brasil.

Partindo dessa lógica Andrade sustenta que:

A seletividade é, portanto, a função real e a lógica estrutural de funcionamento do SJC, comum às sociedades capitalistas patriarcais. E nada simboliza melhor a seletividade do que a clientela da prisão ao nos revelar que a construção (instrumental e simbólica) da criminalidade - a criminalização - incide seletiva e estigmatizantemente sobre a pobreza e a exclusão social, majoritariamente masculina, e apenas residualmente (embora de forma crescente) feminina. (2005, p. 81) 
Nesse sentido, pode-se afirmar que a protagonista é vítima duas vezes do sistema penal, isto é, no momento em que não tem a resposta adequada após ser violentada de diversos modos e no instante em que sobre ela incide a seletividade nefasta típica desse sistema.

\section{CONSEQUÊNCIAS EXTRAJURÍDICAS}

Além das consequências jurídicas aqui apresentadas, as situações apresentadas no filme permitem que se faça uma análise de consequências, principalmente no âmbito social, que se apresentam para a personagem Preciosa e também suas amigas.

Nesse sentido, o filme apresenta uma alternativa para que a protagonista seja capaz de sair das várias crises de violência que enfrenta: o empoderamento feminino e a educação. $\mathrm{Na}$ narrativa cinematográfica a professora Blu Rain e a assistente social Sra. Weiss objetivam a mudança social de Preciosa por meio do empoderamento.

O termo empoderamento advém de uma adaptação para o português de duas palavras da língua inglesa, o substantivo power e o verbo empower. No contexto da realidade cinematográfica analisada neste texto trata-se de um termo cunhado pelo movimento feminista negro para designar o "roll de ações e estratégias de luta de todos os movimentos por emancipação e libertação sociopolítica.” (BHERT, 2018, p. 103).

O empoderamento, ainda, pode ser entendido "enquanto prática que parte do processo de autoconscientização e culmina em transformação" (BERTH, 2018). Nesse aspecto, o trabalho desenvolvido pelas personagens da professora e da assistente social merecem destaque. Durante as conversas com Preciosa, a assistente social Sra. Weiss tenta descobrir o que realmente acontecia na casa da protagonista, que nunca conseguia contar a verdade. Entretanto, depois de uma das várias brigas entre Preciosa e sua mãe, a garota finalmente começa a contar a verdade do que acontecia em sua casa para a Sra. Weiss, motivo que leva a perda do benefício social e consequente aumento da raiva da mãe em relação à Preciosa.

O empoderamento também pode ser percebido na convivência entre Preciosa e suas colgas de sala na Escola alternativa, pois a partir do momento em que a protagonista conhece outras meninas que também passam por diferentes problemas, ela passa a se sentir mais confiante para falar de seus sentimentos e compartilhar suas experiências. Tal fato é reforçado pelas próprias características da sala de aula: formada por mulheres, mais ou menos da mesma idade, todas com algum tipo de problema pessoal, a grande maioria negra e por uma professora, 
também negra (e que, posteriormente, se apresenta como homossexual) que conduz os debates e auxilia as alunas na sua formação.

Outro fator crucial para a mudança de atitude de Preciosa é o papel exercido pela Professora Blu Rain. Rain se apresenta logo que Preciosa chega à nova escola e, desde o primeiro momento, se mostra uma pessoa diferente em relação à garota, não a tratando simplesmente como mais uma em sala de aula. A atitude da professora, como mencionado no capítulo 2, faz com que Preciosa tome consciência de si mesma, enquanto protagonista da sua própria história. Se antes ela apenas se limitava ao mundo dos sonhos - em várias passagens do filme é possível ver a garota "parada no tempo", apenas sonhando com um futuro completamente impossível de se alcançar naquele momento - , após o contato com a professora ela passa a ter condições reais de dar um rumo para sua vida e poder sonhar com um futuro real.

Outro ponto importante está relacionado à questão racial. É possível perceber, durante as cenas na sala de aula da escola alternativa, que todas as meninas ali presentes sofreram algum tipo de discriminação em razão da cor. Preciosa, nesse sentido, não se vê imune a isso, tanto que há cenas em que ela se olha no espelho e se vê como uma menina branca, loura e magra, como se isso fosse condição para se alcançar sucesso e visibilidade social.

Conforme Joice Bhert, em sua obra sobre o conceito de empoderamento:

\begin{abstract}
O posicionamento de mulheres negras é um divisor de águas para toda a luta feminista, uma vez que levanta questionamentos acerca da homogeneidade do ser feminino universal, cunhado por mulheres brancas dentro do feminismo e ressignifica todo o trabalho de empoderamento partindo desse lócus social que, invariavelmente, abarca outros entendimentos que envolvem as opressões em outros níveis, inclusive determinando sua diversidade e complexidade que adquire a medida que se insere nas realidades adjacentes dos grupos minoritários. (2018, p. 49)
\end{abstract}

O sucesso do empoderamento negro feminino no filme pode ser confirmado ao longo do desenvolver da história, que vai mostrando a evolução do pensamento das personagens da sala de Preciosa, que passam a se ver como meninas capazes de alcançar seus sonhos. Uma cena interessante que confirma essa evolução se dá durante uma aula, quando uma das alunas deixa transparecer que o único trabalho que conseguiria seria como empregada doméstica e, na sequência, suas colegas de sala mostram que ela pode ter outro futuro que não este. Nesse momento, a atuação de Preciosa é importante, ao demonstrar matematicamente o quanto uma colega que já esteve nesse lugar ganhava em termos de salário, considerando as horas efetivamente trabalhadas e o salário pago, que não correspondia à realidade. Na última cena do 
filme a questão do empoderamento feminino vem à tona novamente, com Preciosa assumindo seu papel dentro da sociedade - de mãe, ao assumir a criação dos seus dois filhos - e também de mulher capaz de alcançar o que quiser, quando ela conta para a assistente social que tinha alcançado a média necessária na prova do ensino fundamental e começaria a cursar o médio e já pensava na faculdade, o que reforça, também, a importância que a educação teve na sua vida.

O ápice do empoderamento de Preciosa, entretanto, é expressado na cena em que ela, pensando sobre a suas características físicas - que sempre a fizeram sentir-se feia e inferior lembra de uma fala da professora Rain, que afirmou que ela era bonita daquele jeito. Nesse momento, Preciosa se olha no espelho e, pela primeira vez, se sente bonita daquele jeito, como ela realmente era, preciosa. Ou seja, como afirmado por Berth (2008), empoderar é conduzir o indivíduo por diversos estágios de "autoafirmação, autovalorização, autorreconhecimento e autoconhecimento de si mesmo".

O empoderamento pode até mesmo ser utilizado na tão falada paz, isto é, a ausência de violência depreendida da obra de Johan Galtung sobre a Teoria do Confllito na qual o sociólogo trabalha três formas de violência: pessoal, estrutural e cultural. Neste sentido, para que cheguemos à paz é preciso ações sociais de não violência e uma delas pode se dar por meio do empoderamento. (1969)

Todas as ações supracitadas servem para demonstrar como o empoderamento feminino é capaz de alterar situações e conferir esperança à essas meninas que, até então, não eram capazes de vislumbrar um futuro de sucesso e diferentes possibilidades. Empoderar, nesse sentido, é tirar o indivíduo da condição de invisibilidade social e transformá-lo em protagonista da sua própria história.

\section{CONSIDERAÇÕES FINAIS}

A análise do papel do feminino e da violência sofrida pela mulher a partir do filme Preciosa trouxe possibilidades de discussão de importantes pontos de vista.

Partindo-se da premissa da invisibilidade social, foi possível identificar várias situações em que a personagem Claireece Preciosa se sentiu invisível perante a sociedade, também foi possível discutir como o papel dos outros na construção dessa invisibilidade: como a sociedade contribui para que o outro se sinta invisível? 
O capítulo seguinte trabalhou a questão da violência sofrida por Preciosa a partir da Legislação Penal brasileira. Assim, várias faces da violência foram apresentas, desde a violência física - aqui estudada a partir da Lei Maria da Penha - até a violência sistêmica do próprio direito penal, apontado quais as consequências jurídicas possíveis para cada caso estudado.

O último tópico abordou as consequências extrajurídicas das violências sofridas por Preciosa, elucidando a importância do empoderamento feminino e da educação, como fatores de mudança social.

A partir de todos os argumentos apresentados, e tendo em vista a problemática central da pesquisa, qual seja, a de criar um paralelo entre o enredo do filme e o mundo jurídico e sociológico, é possível apresentar algumas considerações finais.

A primeira delas diz respeito ao ambiente de violência em que muitas meninas vivem atualmente. $\mathrm{O}$ filme demonstra claramente que o convívio em um ambiente que reforça somente aspectos negativos da criança/adolescente é capaz de interferir seriamente no seu desenvolvimento psicossocial. Ademais, a violência - física e psicológica - sofrida por Preciosa também trouxe consequências alarmantes, como a gravidez precoce e a dificuldade no aprendizado.

A partir disso, é possível afirmar que esse ambiente contribui significativamente para a percepção da situação de invisibilidade social sofrida pela personagem. Seus problemas eram, no seu ponto de vista, invisíveis para os outros, que não a ajudavam a sair daquele não lugar em que ela se encontrava.

O sentimento de invisibilidade, somado às consequências que diversos e seguidos episódios de violência provocaram em Preciosa, fizeram com que a escola em que ela originalmente estudava a encaminhasse para a escola alternativa. Nesse ponto, é notário o papel que a educação exerceu na mudança de vida de Preciosa. Um ambiente escolar sadio, que considerou as necessidades de cada aluno, que enxergou cada um na sua individualidade, contribuiu para o seu crescimento pessoal e consequente mudança de atitude.

As diversas formas de violência sofridas pela personagem, principalmente a violência sexual, demonstraram que a mulher ainda é subjugada em muitas sociedades, sendo objetificada e exercendo um papel inferior ao masculino. A conversa entre a mãe a assistente social também demonstrou uma realidade que ultrapassa as telas do cinema, de mães que são coniventes com os abusos sexuais sofridos pelos filhos. Ao afirmar que tinha consciência que o pai da sua filha, seu namorado, abusava sexualmente da criança, e não tomar nenhuma atitude que impedisse a 
ação violenta, a mãe se mostrou conivente com o namorado, aceitando a violência e reforçando o papel de inferioridade atribuído pelo namorado às mulheres ao seu redor.

A maior lição trazida pelo filme e pela análise em questão, está em demonstrar que, apesar de todas as adversidades, um novo caminho é possível para essas meninas e mulheres que sofrem, a todo momento, todo o tipo de violência, abuso e discriminação. Que não é preciso se sentir inferior, invisível aos olhos dos outros. A educação, a valorização das pequenas conquistas, o afeto, a atenção e o empoderamento são ferramentas importantes e fundamentais para a mudança de cenário.

A violência contra a mulher deve ser reconhecida, enfrentada e combatida, para que um novo futuro se abra para essas meninas, para que elas possam sonhar, para que elas possam conquistar seus sonhos, possam ser o quiserem ser e, acima de tudo, possam se sentir preciosas, não para os outros, mas para si mesmas.

\section{REFERÊNCIAS}

ANDRADE, Vera Regina Pereira de. A soberania patriarcal: o sistema de justiça criminal no tratamento da violência sexual contra a mulher. Revista Sequência, ${ }^{\circ}$ 50, p. 71-102, jul. 2005. Disponível em:

https://periodicos.ufsc.br/index.php/sequencia/article/view/15185/13811 Acesso em: 10 abr. 2019.

BARSTED, L. L.; PITANGUY, J. O progresso das mulheres no Brasil: 2003 -2010. Rio de Janeiro: Cidadania, Estudo, Pesquisa, Informação e Ação (Cepia). Brasília: Entidades das Nações Unidas para a Igualdade de Gênero e o Empoderamento das Mulheres (ONU Mulheres), 2011.

BERTH, Joice. O que é empoderamento? Belo Horizonte: Letramento, 2018.

BRASIL. Decreto Lei 2.848 de 07 de dezembro de 1940. Código Penal. Disponível em: <http://www.planalto.gov.br/ccivil_03/Decreto-Lei/Del2848compilado.htm>. Acesso em: 11 abr. 2019. 
BRASIL. Lei 11.343 de 23 de agosto de 2006. Disponível em: <http://www.planalto.gov.br/ccivil_03/_Ato2004-2006/2006/Lei/L11340.htm>. Acesso em: 11 abr. 2019.

DIAS, Maria Berenice. Lei Maria da Penha: a efetividade da Lei 11.340/06 de combate à violência doméstica e familiar contra a mulher. 4. ed., rev. , atual. e ampl. São Paulo: Revista dos Tribunais, 2015.

GALTUNG, Johan. Violence, Peace, and peace research. Journal of Peace Research. Sage Publications, Ltd. Noruega, v. 6, n 3, p. 167-191, 1969.

SUPERIOR TRIBUNAL DE JUSTIÇA (STJ). A jurisprudência do STJ nos 11 anos de Lei Maria da Penha. Disponível em:

<http://www.stj.jus.br/sites/STJ/default/pt_BR/Comunica\%C3\%A7\%C3\%A3o/noticias/Not\% C3\%ADcias/A-jurisprud\%C3\%AAncia-do-STJ-nos-11-anos-da-Lei-Maria-da-Penha>.

Acesso em: 10 abr. 2019.

TOMÁS, Júlia Catarina de Sá Pinto. A invisibilidade social, uma perspectiva fenomenológica. Mundos sociais: saberes e práticas. 2008. p. 1-7, série 285. Disponível em: <https://dialnet.unirioja.es/servlet/articulo?codigo=4561886>. Acesso em: 11 abr. 2019. 